\title{
EVALUATION OF FREIGHT MEASURES BY INTEGRATING SIMULATION TOOLS: THE CASE OF VOLOS PORT, GREECE
}

\author{
Ioannis Karakikes ${ }^{1}$, Wladimir Hofmann ${ }^{2}$, Lambros Mitropoulos ${ }^{3}$, Mihails Savrasovs ${ }^{4}$ \\ ${ }^{1}$ Universiy of Thessaly, Department of Civil Engineering \\ Volos, Greece, Pedion Areos, 38334 \\ iokaraki@uth.gr \\ ${ }^{2}$ Fraunhofer Institute for Factory Operation and Automation IFF \\ Magdeburg, Germany, Sandtorstr. 22, 39106 \\ wladimir.hofmann@iff.fraunhofer.de \\ ${ }^{3}$ University of Thessaly, Department of Civil Engineering \\ Volos, Greece, Pedion Areos, 38334 \\ lmit@civ.uth.gr \\ ${ }^{4}$ Transport and Telecommunication Institute \\ Riga, Latvia, Lomonosova street 1, LV-1019 \\ savrasovs.m@tsi.lv
}

\begin{abstract}
Simulation modelling tools have been widely adopted for the evaluation of alternatives in transport planning, management and logistics. The complexity that underlies in transport systems and logistics necessitate the integration of different models that are capable of overcoming limitations that may exist individually to each model. Towards this direction, this paper aims to integrate two simulation software and use the integrated model for the evaluation of traffic and logistics measures in the wider area of Volos Port, Greece. The built model is able to simulate the traffic conditions on a transport network along with port's intra-logistics processes and is used to evaluate a set of measures in the year 2030, by comparing it with the situation in the year 2030 without having implemented any new measure. For the evaluation, a set of indicators is used to gauge the environmental and transport impacts. The analysis is completed by using a multi-criteria decision making tool to generate the Logistics Sustainability Index (LSI) to summarize the information that is provided by the indicators. The results show that the use of integrated simulation models can provide a holistic impact evaluation of complex decisions with a high level of accuracy.
\end{abstract}

Keywords: Software integration, City Logistics, Transport interchanges

\section{Introduction}

Urban freight transport constitutes one of the biggest problems that modern cities have to deal with today, as it can produce many adverse impacts (economic, environmental, societal and transport) and deteriorate the quality of life for citizens of urban areas. Impacts occurring from different logistics measures can be estimated by using simulation tools. Simulation provides a comprehensive way for engineers to test and explore different measures under various assumptions and conditions for long- term planning by considering local geographic, transport and legal characteristics. A wide-range of simulation software has been developed for transport and logistics modelling based on data or agents. Although these simulation software adopt partly similar approaches, their strengths and weaknesses make them suitable for different problems. The complexity that underlies in transport systems and logistics necessitate the integration of different models that are capable of overcoming limitations in modelling and suggesting the best measure to support sustainable planning.

Simulation modelling represents a widely-used tool for urban planning, traffic management and logistics, especially in the field of commercial ports, where a number of studies has been conducted. Dragovic et al. (2017) provided a comprehensive overview of port simulation modelling for the last 20 years, highlighting the growing importance and the increasing popularity of the Discrete-EventSimulation (DES) approach. Lin et al. (2014) and Hou and Geerlings (2016) investigated planning alternatives in terms of economic impacts and environmental effects towards port sustainability. Cimpeanu et al. (2017) use simulation not only to evaluate long-term planning but also to support port operations as maintenance scheduling. Schipper et al. (2017) analyze related systems such as hinterland connections and the urban situation around the ports to cope with the various challenges of sustainable and efficient port development and operations. 
Systems as commercial ports consist of many interrelated sub-systems with various interdependencies. To investigate the behaviour of interrelated sub-systems of different types, different simulation models and approaches can be linked (Fakhimi et al., 2013). This process is known as hybrid simulation or as hybrid systems modelling approach (Elbadi et al., 2016). Modern simulation tools typically offer different possibilities for interfacing. Mittal and Krejci (2015) showed how an agent-based model can be linked with a DES model by storing results in output-files which then become inputs to the other model. Fellendorf and Vortisch (2010) explained how to control a running simulation via its COM interface for a more dynamic integration. However, when multiple tools need to be linked it can be cumbersome and error-prone to manually implement pairwise connections between all tools. The most widely used approach to enable different simulation systems to work together in a distributed environment is the High Level Architecture (HLA), which was used by Jain et al. (2015) to evaluate sustainability in urban systems.

This study aims at integrating two simulation software for evaluating a set of logistic measures in Volos Port, Greece, based on environmental and transport impacts. The study area is of high interest to the city of Volos since expected development of the port by 2030 will lead to increased traffic flows and emissions (Greek coasting, 2017).

\section{Methodological Approach}

In order to simulate urban traffic and transportation systems, different approaches can be found in literature. Hofmann et al. (2017) presented an Open-Street-Map-based simulation tool in which transport processes are simulated taking into account realistic distance matrices. However, vehicle speed profiles and transport process durations, are roughly estimated, leaving room for a more detailed consideration of vehicle movements. In this paper, the relation between port operations and the transport of containers and bulk shipments on the connected road network is examined in order to perform a holistic impact assessment. The flowchart in Figure 1 presents the methodology that is developed to integrate two different software (AnyLogic and VISSIM) to assess freight measures.

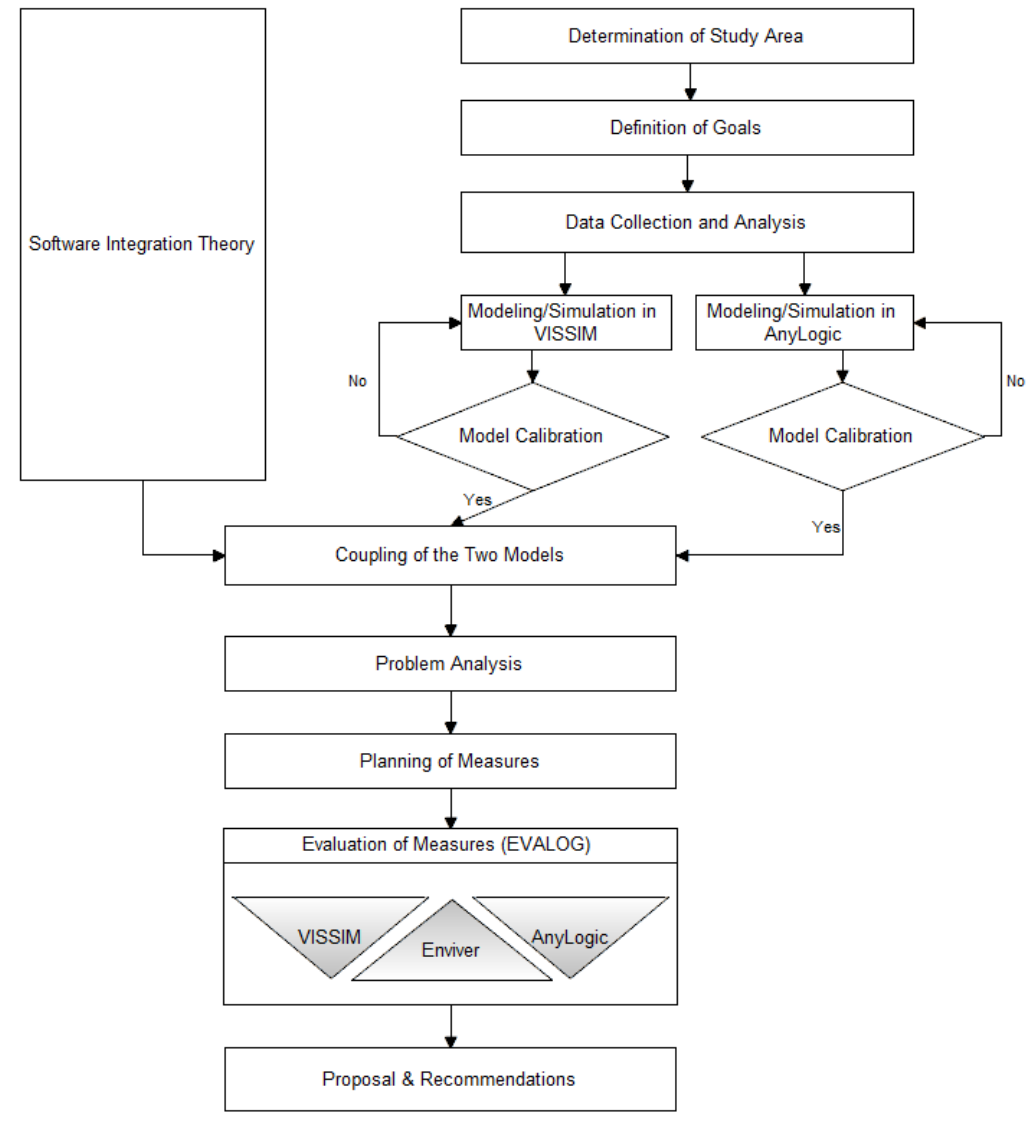

Figure 1. Methodological approach 


\subsection{AnyLogic model}

Basic linear bulk and container loading processes for Heavy Good Vehicles (HGVs) are simulated and animated using the discrete event simulation process modelling library of AnyLogic. Figure 2 shows a screenshot of the simulation model animation. HGVs enter the security check at the gate and then they move either to the bulk handling terminal or to the container terminal. There, they load stacker units, modelled as moving resources, and start their movement towards the exit.

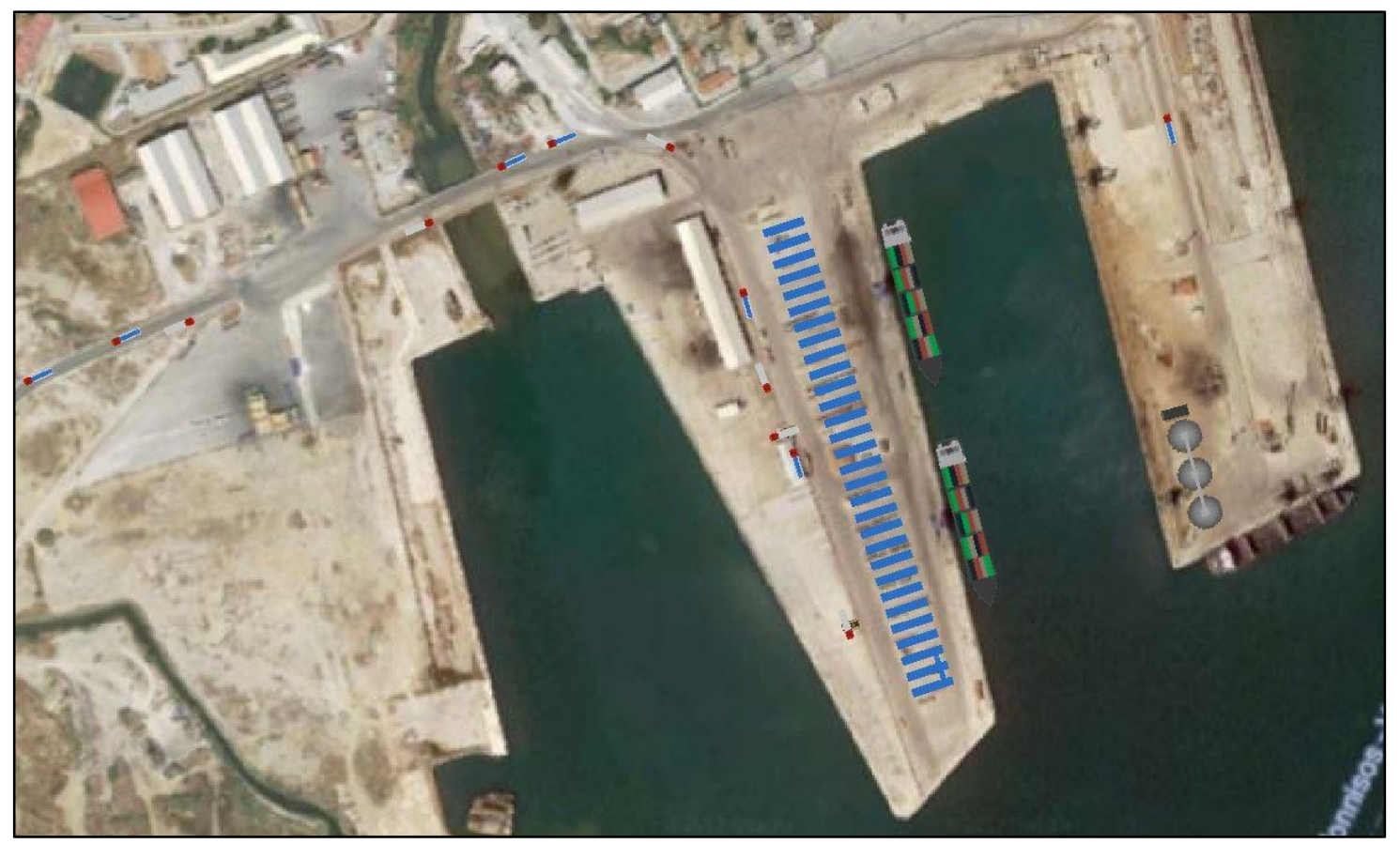

Figure 2. Port Simulation model animation

The GIS feature of AnyLogic is used to provide an overview of the location of HGVs in the road network after having left the port. The built in Open Street Map (OSM) connection enables the model to take into account realistic road lengths as well as one-way streets and mode-specific route choices. This is well suited to provide a basis for early-stage planning simulations of transport logistics systems (Hoffmann et al., 2017).

\subsection{VISSIM model}

AnyLogic includes a library for microscopic traffic simulation, but due to significantly decreased possibilities for parameterization VISSIM was chosen to simulate the traffic flow in the transport network around the port. Figure 3 shows the entry point of the HGVs in the VISSIM model.

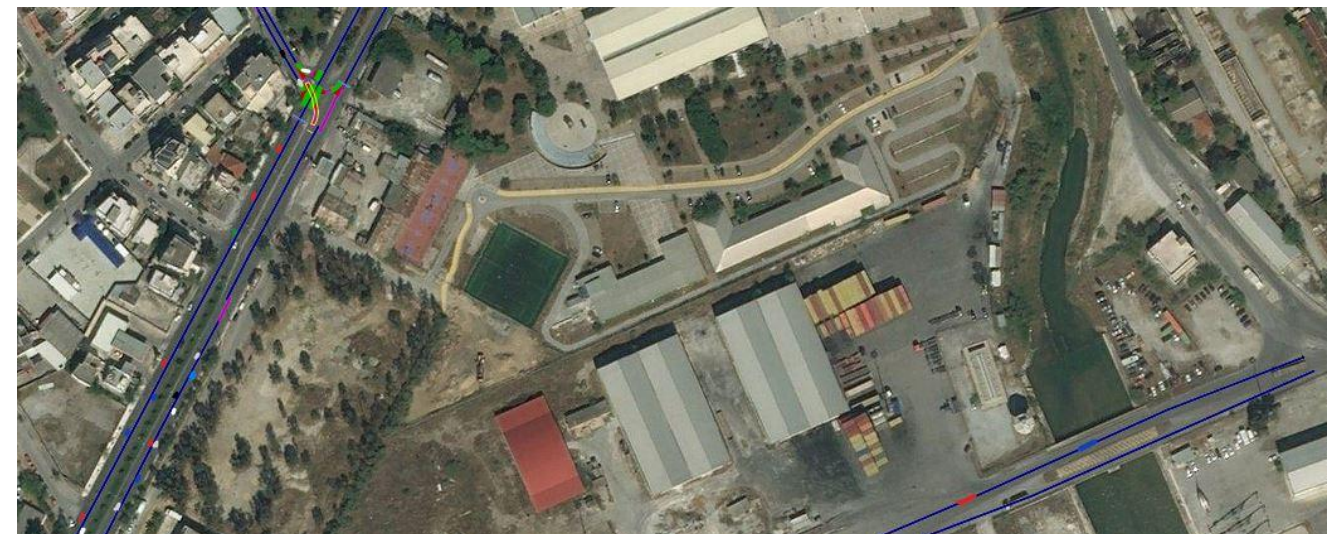

Figure 3. Sub-section of the VISSIM model with HGV entry point 
For the evaluation of the model a total number of 10 simulation runs with different random seeds was decided in order to guarantee representative normalized results. The warm-up period was set equal to 900 seconds in order to load the network realistically before the beginning of the evaluation of the results. In order to ensure a validated representation of reality, the model was calibrated by checking for coding errors and false insertion of input data while adjusting various parameters iteratively until results fall within certain thresholds (Karakikes et al., 2016). The acceptance tolerances were determined according to Wisconsin DOT (2017).

\subsection{Software Integration}

The connection of VISSIM and AnyLogic is done via the VISSIM COM interface. AnyLogic is configured as the master application, controlling the VISSIM model via the JAva COm Bridge (JACOB) and corresponding COM commands as specified in the VISSIM COM API (Clay_shooter, 2017). Analytically, the network files are loaded and the simulation is run in a synchronized manner, always running for the time until the next event in AnyLogic. Whenever a HGV is reaching the exiting point of the port, a corresponding vehicle is inserted into the VISSIM network at the specified entry point location.

The geo-reference of the inserted vehicle is stored in AnyLogic to enable the query of status data such as location and current speed of the HGV, which then can be used to keep the GIS-map animation synchronized with the actual status in VISSIM. The GIS-map HGVs move autonomously, but their speed and location are cyclically synchronized to correct deviations regarding speed and route choice. Due to the fact that location coordinates are handled differently in VISSIM and AnyLogic (VISSIM uses Mercator coordinates and AnyLogic WGS84 coordinates), a conversion of the coordinates based on the VISSIM reference was necessary (Fig. 4).

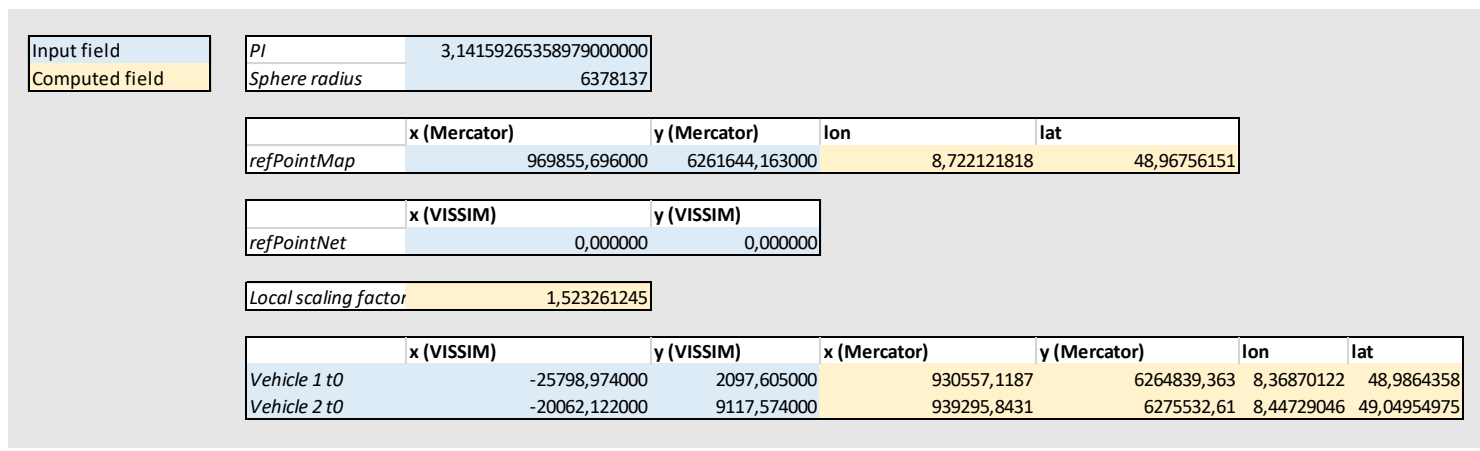

Figure 4. Conversion of coordinates

\subsection{EnViVer model}

To estimate the environmental impact of the measures, the EnViVer software was used. EnViVer is based on VERSIT+ exhaust emission model and has been designed by TNO. There is a significant number of publications demonstrating EnViVer software's successful application in practice (Linton et al., 2015; Borge et al., 2014; Quaassdorff et al., 2016).

EnViVer takes vehicles' trajectories data generated by Vissim simulation software for different vehicle classes (Light-duty, Bus and Heavy-duty), road types (Urban, Highway) and fuel types (petrol, diesel, LPG, CNG, electric) and provides accurate pollutant emissions $\left(\mathrm{CO}_{2}, \mathrm{NO}_{\mathrm{X}}, \mathrm{PM}_{10}\right)$ measurements considering individual driving patterns (speed and acceleration data), vehicles' properties (weight and power) and particularities of the transport network (gradient of the roads sections, defined in VISSIM). To export reliable results, EnViVer considers additional data about the age distribution of the vehicles by setting up parameters, such as \% of vehicles newer than 1 year, average vehicle age and average exit age. The determination of the aforementioned parameters together with emission legislation data produces the distribution of the vehicles by the euro norm. Table 3 below, demonstrates the input data used in EnViVer. 
Table 1. Parameters for EnViVer

\begin{tabular}{|c|c|c|}
\hline Parameters & Values & \\
\hline Road Type & Urban & \\
\hline Vehicles newer than 1 year: $\%$ & $5 \%$ & \\
\hline Average vehicle age: (years) & 13.5 & \\
\hline Average exit age (years) & - & \\
\hline Euro legislation introduction: & $\begin{array}{l}\text { Euro } 1 \text {-1993 } \\
\text { Euro } 2 \text { - } 1996 \\
\text { Euro } 3 \text { - } 2000 \\
\text { Euro } 4 \text { - } 2005 \\
\text { Euro 5- } 2009 \\
\text { Euro } 6 \text { - } 2014\end{array}$ & \\
\hline & 2017 & 2030 \\
\hline Vehicle Type: Heavy-Duty & $\begin{array}{l}\text { Petrol: } 0 \% \\
\text { Diesel: } 100 \% \\
\text { CNG: } 0 \% \\
\text { Electric: } 0 \%\end{array}$ & $\begin{array}{l}\text { Petrol: } 0 \% \\
\text { Diesel: } 78 \% \\
\text { CNG: } 2 \% \\
\text { Electric: } 20 \%\end{array}$ \\
\hline Vehicle Type: Light-duty & $\begin{array}{l}2017 \\
\text { Petrol: } 92.53 \% \\
\text { Diesel: } 6.41 \% \\
\text { CNG: } 1.05 \% \\
\text { Electric: } 0.01 \%\end{array}$ & $\begin{array}{l}2030 \\
\text { Petrol: } 79.55 \% \\
\text { Diesel: } 6.41 \% \\
\text { CNG: } 1.05 \% \\
\text { Electric: } 1.82 \%\end{array}$ \\
\hline
\end{tabular}

\section{Application in Urban Freight Measures}

To promote sustainable transport planning for the area of the commercial port of Volos in the year 2030 and support stakeholders, a traffic volume forecast has been carried out for further investigation. Based on the results of the forecast, a 144\% increase of cargo shipment loads is expected by 2030 due to further development of the port which will be added to the additional induced traffic due to the growth of the city (Hellenic Statistical Authority, 2017; Port Authority of Volos, 2017). This will bring a higher number of HGVs using the network around the port which will set the adoption of new measures as an imperative necessity in order to keep the same level of traffic performance in the network.

To quantify the impacts of the future situation a base scenario (without any measure implementation) and a scenario (with measure implementation) for the year 2030 were modelled and evaluated. Within the two scenarios projections of population (based on economic indexes) as well as port's development were considered.

\subsection{Data}

Traffic volumes and the percentage of HGVs derived from on-site measurements which were realized during a weekday in June 2017, representing a "typical" day (Karakikes et al., 2018). A preliminary analysis was conducted to determine the peak hour (09:45 a.m. - 10:45 a.m.). Traffic lights' programs were given by the Traffic Management Centre of the city of Volos. The remaining operational elements of the VISSIM model were determined either from Google maps or from on-site observation.

The cargo shipment loads on a monthly basis as well as loading/unloading, storing and scheduling information were given by the Port Authorities both for containers and bulk loads. Except for the loads all other information was given empirically by Port's Traffic Management Office due to the absence of official records.

\subsection{Measures and scenarios}

The selected measures to be modelled are a combination of traffic and logistics measures. Their selection was based on the following criteria:

- Soft measures (no structural interventions)

- Intelligent Transport Systems (ITS) oriented

- Low cost implementation

In the following sections measures' description, implementation results and modelling efforts that differentiate the scenario with the measures from the base scenario, are presented. 


\section{Measure 1 -Real time online system for better monitoring}

Description: This measure aims at increasing the load factor of the HGVs that carry bulk shipments. According to the authorities of Volos port, nearly half of the HGVs are used to carry such shipments (mainly corn and grain) with an average load factor of $85 \%$. These HGVs could achieve higher load factors if there was a real-time online system that could provide information to the carriers (volume of the remaining product so as to choose the most appropriate truck type/size, information about unexpected events due to poor programming, etc.).

Implementation result: The adoption of information systems in conjunction with better programming could end up to an average $95 \%$ load factor.

Modelling effort:

- $5.5 \%$ reduction of $\mathrm{HGV}$ s entering/exiting the commercial port

- Weight distribution for $50 \%$ of HGVs has been increased (10\%).

Measure 2 - Green fleet

Description: The second measure focuses on the share of HGVs that are powered by alternative fuels. The share of CNG and Electric HGVs can be increased by $2 \%$ and 3\%, respectively, (meaning $-5 \%$ of Diesel HGV) according to EU projections, the percentage of local sales of alternative fuel vehicles and the expected market penetration of alternative fuel vehicles. The increase can derive from tax incentives and campaigns promoting the benefits of new technology vehicles.

Implementation result:

- Diesel HGV: $73 \%$ (from 78\%)

- Compressed Natural Gas HGV: $4 \%$ (from $2 \%$ )

- Electric HGV: $23 \%$ (from 20\%)

Modelling effort: Change the parameters of share for "Heavy-Duty" vehicles to estimate the environmental impacts, in EnViVer software.

\section{Measure 3 - Local traffic management}

Description: This measure focuses on ITS adoption for control and traffic management. Specifically, the third measure improves the "green wave" for the three successive intersections on the tested corridor and based on the calibrated simulation model, a better coordination is achieved by slightly offsetting earlier the signals of the last two intersections. Green wave preconditions are fully covered (Wu et al., 2014).

Implementation result: Minimization of the percentage of vehicles that drive through the intersection without stopping, allows loaded HGVs to avoid unnecessary deceleration and acceleration which results to smoother rolling with fewer emissions and noise, and lower fuel consumption.

Modelling effort: Offset the signal programs of the last two intersections of our network, by 8 and 6 seconds earlier.

\subsection{Evaluation}

The three measures were evaluated all together in the two scenarios. The evaluation of scenarios was performed by using an online platform (Evalog) that enables aggregation of selected components (i.e., indicators, criteria, impact areas, etc.) into the Logistics Sustainability Index (LSI). The platform formulates a multi-criteria multi-stakeholder decision making approach (Nathanail et al., 2016). Aggregation of indicators results into a single index that reveals the sustainability of a scenario relative to another scenario. Addition among indicator with different units is performed only after the different measurement units are normalized into a dimensionless scale. For this study indicators are normalized and aggregated by using the weighted sum method. Indicators are grouped into two impact areas: Environment and Transport performance. Equal weights of 0.5 are assigned to the impact areas of Environment and Transport performance.

Three environmental indicators $\left(\mathrm{CO}_{2}, \mathrm{NO}_{\mathrm{X}}, \mathrm{PM}_{10}\right)$ and one transport based indicator (Delays) are used in this evaluation after ten simulation runs by using the developed integrated simulation model. The indicator "Delay" represents the sum of delays of all vehicles within the peak hour were measured for the whole network both in VISSIM and AnyLogic model. Environmental indicators values are quantified by EnViVer software based on the VERSIT+ exhaust emission. Since indicators within each impact area are equally weighted too, all three environmental indicators are weighted by 0.166 and the indicator "delay" is weighted by 0.5 . 


\section{Results}

The results show that the implementation of the set of measures in the year of 2030 (Scenario 2) improves the overall performance of the transport network. Analytically, the values of the environmental indicators decrease by 7-9\%, while the sum of delays in the network decrease even more (26\%), Figure 5. The higher decrease in "Delays" can be partially attributed to Measure 1 which on the one hand decreases the number of HGVs moving in the network, thus, the delays, but on the other induces more emissions owing to the $10 \%$ increase of weight distribution. The Scenario 2 LSI value increase $(21 \%)$ is in accordance with the improvement of indicators' values, since it is determined equally by the environmental and the transport indicators.

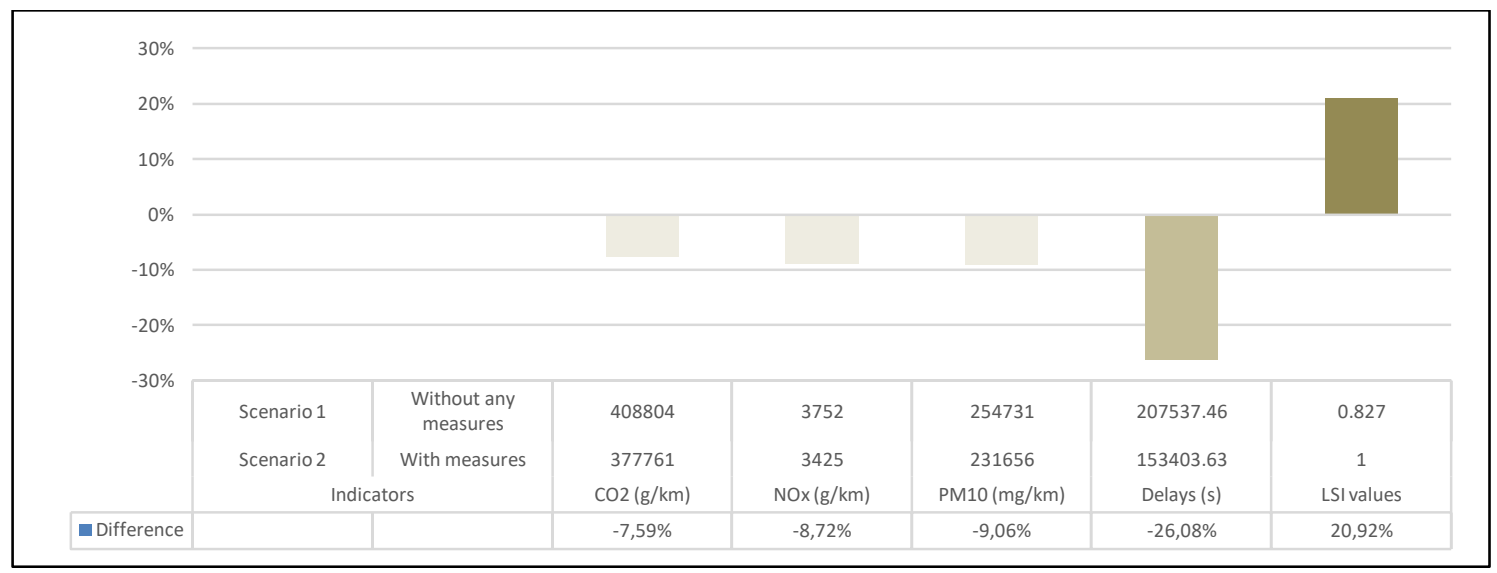

Figure 5. Before and after values for indicators and LSI

Specifically, the impact area "Transport and Mobility" expressed through the transport indicator "Delays" achieve a higher improvement as compared to the "Environment" which scores 0.915 for the Scenario 1 and 1.000 for Scenario 2, Figure 7. It worth to be mentioned that the 1.000 values in Scenario 2 stems from the normalization process that EVALOG platform follows which gives this score to the "best" scenario. In no case, it is implied that the achieved situation in Scenario 2 cannot be further improved with the implementation of additional measures.

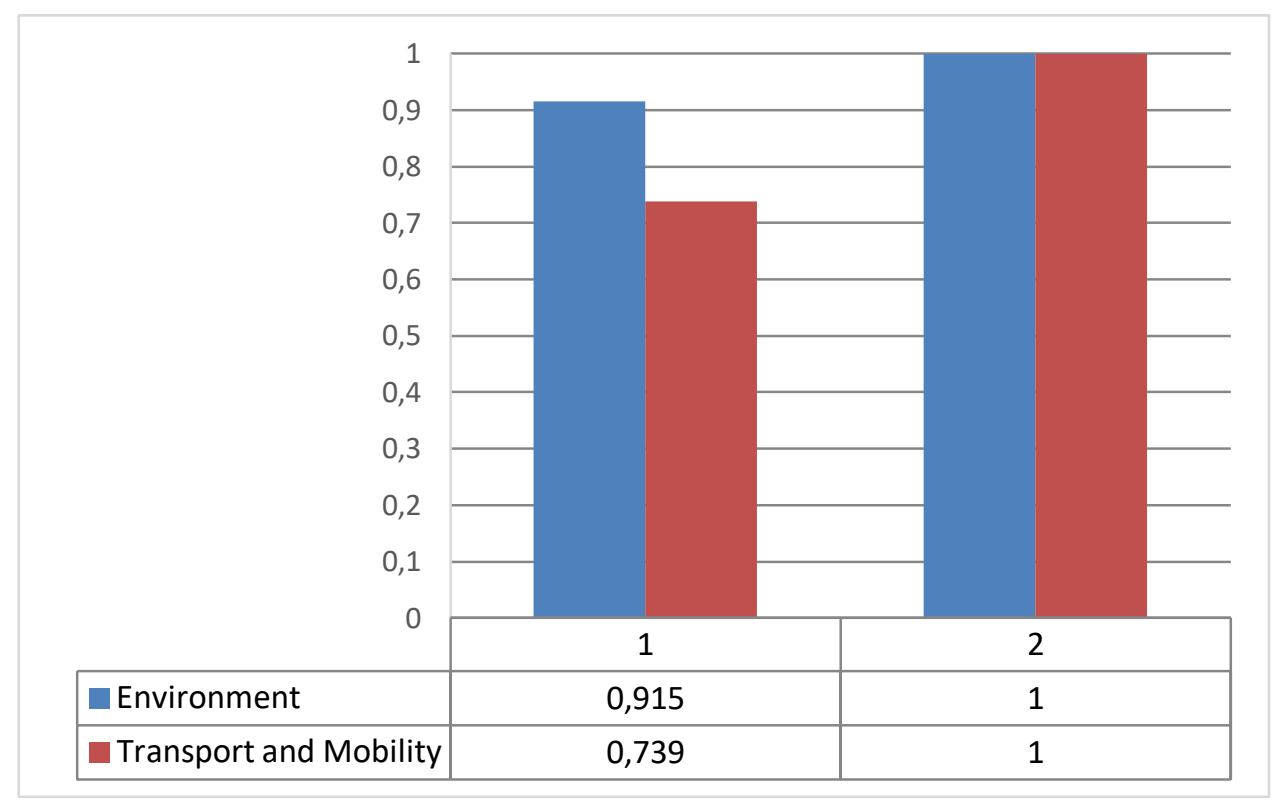

Figure 6. Impact Areas Index Graph 


\section{Discussion}

Commercial ports constitute complex transport systems consisting of individual subsystems with different characteristics and components. The road network in and out the commercial ports as well as the loading/unloading and storage of cargo are such subsystems that require thorough analysis to maintain a high level of performance, as they often affect the traffic of goods as well as the traffic of the vehicles that move in the area around the port. This paper presents a methodology for evaluating urban freight measures to promote sustainability in the year of 2030, using the example of the commercial port of Volos, Greece. In the analysis two major subsystems are considered; the transport network around the commercial port and the intralogistics processes (loading, unloading, programming etc.) inside the area of the port. To analyze and understand the transport network around the commercial port a traffic micro simulation software was used, while for the analysis of the intralogistics processes, a multimethod simulation software. The two software were selected in that way as each one per case can simulate adequately the operations and the behaviour of the subsystem, while it allows easy parameterization for the scenario building. The two developed models were calibrated and validated, and then were integrated to simulate the overall transport system of the port. The final integrated model is able to evaluate comprehensively the complex system of the port and to provide synthetic results from the two software.

In this case study, the results indicate that by implementing all three measures at the same time, the traffic performance and the level of emissions owing to the traffic around the port in the year 2030 are significantly improved. The lack of economic data, does not allow the completion of a cost-benefit analysis, however, it can be safely concluded that the above measures, in combination with hard measures, may contribute to the economic sustainability of the system, as well.

Furthermore, the methodological approach followed can serve as a guidebook for future studies willing to assess holistically transport systems such as transport interchanges, commercial ports or urban consolidation centres, since it connects a facility's intra-processes with the transport network nearby.

\section{Acknowledgements}

This work has been supported by the ALLIANCE project (http://alliance-project.eu/) and has been funded within the European Commission's H2020 Programme under con-tract number 692426. This paper expresses the opinions of the authors and not necessarily those of the European Commission. The European Commission is not liable for any use that may be made of the information contained in this paper.

\section{References}

1. Borge, R., Lumbreras, J., Pérez, J., de la Paz, D., Vedrenne, M., de Andrés, J., Rodríguez, M. (2014) Emission inventories and modelling requirements for the development of air quality plans. Application to Madrid (Spain). Science of the Total Environment. 466-467, 809-819 (2014).

2. Cimpeanu, R., Devine, M.T., O’Brien, C. (2017) A simulation model for the management and expansion of extended port terminal operations. In: Transportation Research Part E: Logistics and Transportation Review 98, pp. 105-131. DOI: 10.1016/j.tre.2016.12.005.

3. Clay_shooter (2017) JACOB - Java COM Bridge. Available online at https://sourceforge.net/projects/jacob-project/.

4. Dragović, B., Tzannatos, E., Park, N.K. (2017) Simulation modelling in ports and container terminals. Literature overview and analysis by research field, application area and tool. In: Flex Serv Manuf J 29 (1), pp. 4-34. DOI: 10.1007/s10696-016-9239-5.

5. Eldabi, T., Balaban, M., Brailsford, S., Mustafee, N., Nance, R., Onggo, B. S., Sargent, R. G. (2016) HYBRID Simulation: Historical Lessons, Present Challenges and Futures. In: Theresa M. Roeder, Peter I. Frazier, Robert Szechtman, Enlu Zhou (Eds.): Simulating complex service systems. WSC'16 Winter Simulation Conference: Crystal Gateway Marriott, Arlington, VA, December 11-14, 2016. [Piscataway, NJ], [Piscataway, NJ]: IEEE, pp. 1388-1403.

6. Fakhimi, M., Mustafee, N., Stergioulas, L., Eldabi, T. (2013) A Review of Literature in Modeling Approaches for Sustainable Development. In: R. Pasupathy, S.-H. Kim, A. Tolk, R. Hill, and M. E. Kuhl (Ed.): Proceedings of the 2013 Winter Simulation Conference: IEEE, pp. 282-290.

7. Fellendorf, M. and Vortisch, P., (2010) Microscopic Traffic Flow Simulator VISSIM. In: Jaume Barceló (Ed.): Fundamentals of Traffic Simulation, vol. 145. New York, NY: Springer New York (International series in operations research \& management science), pp. 63-93. 
8. Greek coasting. - http://www.ellinikiaktoploia.net, last accessed 2017/10/09.

9. Hellenic Statistical Authority, - http://www.statistics.gr/en/home, last accessed 2017/6/16.

10. Hofmann, W., Assmann, T., Dolati N., Parisa; C., Van-Dat; Tolujevs, J. (2017) A Simulation Tool to Assess the Integration of Cargo Bikes into an Urban Distribution System. In Bruzzone, Janosy, Nicoletti, Zacharewicz (Eds.): Proceedings of the International Workshop on Simulation for Energy, Sustainable Development \& Environment, 2017, pp. 11-20.

11. Hou, L. and Geerlings, H. (2016) Dynamics in sustainable port and hinterland operations. A conceptual framework and simulation of sustainability measures and their effectiveness, based on an application to the Port of Shanghai. In: Journal of Cleaner Production 135, pp. 449-456. DOI: 10.1016/j.jclepro.2016.06.134.

12. Jain, A., Liu, M., Fujimoto, R., Crittenden, J., Kim, J., Lu, Z. (2015) Towards Automating the Development of Federated Distributed Simulations for Modelling Sustainable Urban Infrastructures. In: Levent Yilmaz (Ed.): Proceedings of the 2015 Winter Simulation Conference, December 6-9, 2015, Huntington Beach, CA. Piscataway, NJ, [Madison, Wis.]: IEEE; Omnipress.

13. Karakikes, I., Mitropoulos L., Savrasovs, M. (2018) Evaluating Smart Urban Freight Solutions Using Microsimulation, Reliability and Statistics in Transportation and Communication, DOI 10.1007/9783-319-74454-4_53

14. Karakikes, I., Spangler, M., Margreiter, M. (2016) Motorway Simulation Using Bluetooth Data, Transport and Telecommunication Journal, Volume 17, Issue 3, Pages 242-251. DOI: 10.1515/ttj2016-0022 (2016).

15. Lin, J., Gao, B., Zhang, C. (2014) Simulation-based investment planning for Humen Port. In: Simulation Modelling Practice and Theory 40, pp. 161-175. DOI: 10.1016/j.simpat.2013.09.009.

16. Linton, C., Grant-Muller, S., Gale, W. (2015) Approaches and Techniques for Modelling CO2Emissions from Road Transport. Transport Reviews. 35, 533-553 (2015).

17. Mittal, A. and Krejci, C. (2015) A Hybrid Simulation Model of Inbound Logistics Operations in Regional Food Supply Systems. In: Levent Yilmaz (Ed.): Proceedings of the 2015 Winter Simulation Conference, December 6-9, 2015, Huntington Beach, CA. Piscataway, NJ, [Madison, Wis.]: IEEE; Omnipress, pp. 1549-1560.

18. Nathanail, E., Gogas, M. and Adamos, G. (2016) Smart interconnections and urban freight transport towards achieving sustainable city logistics. Transportation Research Procedia 14 (2016) 983-992, Elsevier. $6^{\text {th }}$ Transport Research Arena, Warsaw, Poland, April 18-21, (2016). DOI: 10.1016/j.trpro.2016.05.078.

19. Port Authority of Volos, - http://www.port-volos.gr/, last accessed 2017/5/30.

20. Quaassdorff, C., Borge, R., Pérez, J., Lumbreras, J., de la Paz, D., de Andrés, J. (2016) Microscale traffic simulation and emission estimation in a heavily trafficked roundabout in Madrid (Spain). Science of the Total Environment. 566-567, 416-427 (2016).

21. Schipper, C.A.; Vreugdenhil, H.; Jong, M.P.C. de (2017) A sustainability assessment of ports and port-city plans. Comparing ambitions with achievements. In: Transportation Research Part D: Transport and Environment 57, pp. 84-111. DOI: 10.1016/j.trd.2017.08.017.

22. Wisconsin DOT - Department of Transportation, Microsimulion Guidelines, http://www.wisdot.info/microsimulation/index.php?title=Model_Calibration\#The_GEH_Formula, last accesses 2017/5/30.

23. Wu, X., Deng, S., Du, X., Ma, J. (2014) Green-Wave Traffic Theory Optimization and Analysis, World Journal of Engineering and Technology, 2, 14-19 (2014). 